$\mathrm{EC}_{50} \cdot \mathrm{OH}=9.0 \mathrm{mg} / \mathrm{ml}$ ) increased with the addition of $20 \%\left(\mathrm{EC}_{50} \mathrm{O}_{2}{ }^{*}=27.4 \mathrm{mg} / \mathrm{ml} ; \mathrm{EC}_{50} \cdot \mathrm{OH}=2.7 \mathrm{mg} / \mathrm{ml}\right), 30 \%$ $\left(\mathrm{EC}_{50} \mathrm{O}_{2} \cdot=28.0 \mathrm{mg} / \mathrm{ml} ; \mathrm{EC}_{50} \cdot \mathrm{OH}=3.2 \mathrm{mg} / \mathrm{ml}\right)$ and $40 \%$ $\left(\mathrm{EC}_{50} \mathrm{O}_{2} \cdot=28.8 \mathrm{mg} / \mathrm{ml} ; \mathrm{EC}_{50} \cdot \mathrm{OH}=7.9 \mathrm{mg} / \mathrm{ml}\right)$ of dried plums. The obtained results indicate that the honey with dried plums is a new product with high antioxidant activity and their inclusion in the diet may be recommended to complement other polyphenol sources.

\title{
RESEARCH OF EXTRACTION CONDITIONS OF PEPPERMINT AND BOGBEAN RAW MATERIALS AS THE ACTIVE COMPOUNDS OF HERBAL MEDICAL PRODUCT "TRIVALUMEN FORTE"
}

\section{(C) Dobrovolnyi O. O. ${ }^{1}$, Shalamay A. S. ${ }^{1}$, Krutskih T. V. ${ }^{2}$, Slobodianiuk I. ${ }^{2 .}$}

'PJSC SIC "Borshchahivskiy CPP", Kyiv, Ukraine

${ }^{2}$ National University of pharmacy, Kharkiv, Ukraine

Peppermint and bogbean leaves use for preparation of the active substance of the herbal medical product "Trivalumen". The therapeutic role of these components is antispasmodic and choleretic action of phenolic compounds and secretolytic action of iridoids. The works purpose was determination of the optimal extraction conditions of these raw materials in process of herbal medical product "Trivalumen Forte". Raw material was extracted separately by different solvents (93\%, 70\%, $40 \%$ ethanol and water) till the total DER 1:10. Sampling was carried out at interval DER 1:1 for each experiment. In the peppermint and bogbean extracts the amount of total flavonoids was determinated by spectrophotometry. The composition of flavonoid fraction of the peppermint extracts and presence of loganin in the bogbean extracts was identified by TLC. The efficacy of extraction process was assessed using experimental data. The dependency of extraction dynamic of total flavonoids and extractable substances were represented vs. extragent polarity and DER. The optimal conditions of peppermint extract for herbal medical product "Trivalumen Forte" was extraction of raw material by $40 \%$ ethanol at DER 1:7-8. The extract contained not less than $9 \%$ of total of flavonoids in equivalents of gesperidin (dry extract) and composition of this extract include rutin, giperoside, quercitin, chlorogenic and caffeic acids. Yield of extractable substances was not less than $20 \%$. For bogbean extract the optimal extraction conditions of raw material was by $40 \%$ ethanol at DER $1: 6-7$. This extract contained not less than $2.5 \%$ of total flavonoids in equivalents of rutin (dry extract) and characterized by the presence of loganin. Yield of extractable matters was not less than $30 \%$.

\section{THE METODOLOGICAL APPROACH TO THE IRIDOID ANALYSIS IN HERBAL RAW MATERIALS}

\section{(C) Zhogova A. A., Eller K. I.}

Institute of Nutrition RAMS, Moscow, Russia

Iridoids are a large group of cyclopentapyran monoterpenoids widely distributed in nature. Iridoids are represented mainly in dicotyledonous plant families namely Plantaginaceae, Lamiaceae, Asteraceae, Gentianaceae, Rubiaceae, Oleaceae. Medicinal plants containing iridoids have a long history of use in the official and folk medicine as bitter tonics, choleretics, anti-inflammatory and antimicrobial agents, remedies for wounds and skin disorders. Recent studies have shown antioxidant, neuro-, hepato-, cardioprotective and adaptogenic properties of iridoids. A number of iridoidscontaining medicinal plants are included in National Pharmacopoeias of leading countries of the world. In Russian Federation adequate and maximum acceptable intake levels for iridoids (aucubin, harpagoside, oleuropein, asperulosidic deacetylasperulo- sidic acid) were established by «Unified sanitary-epidemiological and hygienic requirements for goods subject to sanitary and epidemiological surveillance (monitoring)». Standardization of iridoids containing herbal materials is hindered by lack of reliable methods for determination of specific indicative iridoids such as aucubin and catalpol for genus Plantago and Veronica, harpagide, leonuride for Leonurus (Lamiaceae), oleuropein for Olea (Oleaceae), loganin for Menyanthus (Menyanthaceae), asperulosidic and deacetylasperulosidic acid for Morinda (Rubiaceae), etc. A quantitative HPLC-DAD/ESI-TOF-MS method was developed for the simultaneous determination of iridoids mentioned above. Optimal chromatographic conditions were achieved using gradient elution with $0.1 \%$ aqueous formic acid and methanol. Analytes were identified 


\begin{tabular}{|c|c|c|c|c|}
\hline Compound & $\mathrm{K}$ & $U V_{\text {max }}(n m)$ & 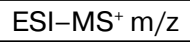 & Ion detected \\
\hline Catalpol & 1,20 & 200 & 385,11 & {$[\mathrm{M}+\mathrm{Na}]^{+}$} \\
\hline Deacetylasperulosidic acid & 1,41 & 235 & 413,10 & {$[\mathrm{M}+\mathrm{Na}]^{+}$} \\
\hline Aucubin & 1,75 & 200 & 369,12 & {$[\mathrm{M}+\mathrm{Na}]^{+}$} \\
\hline Asperulosidic acid & 2,87 & 235 & 455,11 & {$[\mathrm{M}+\mathrm{Na}]^{+}$} \\
\hline Harpagide & 2,37 & 200 & 387,13 & {$[\mathrm{M}+\mathrm{Na}]^{+}$} \\
\hline Leonuride & 2,43 & 200 & 371,13 & {$[\mathrm{M}+\mathrm{Na}]^{+}$} \\
\hline Galiridoside & 2,57 & 200 & 369,12 & {$[\mathrm{M}+\mathrm{Na}]^{+}$} \\
\hline Loganin & 3,45 & 235 & 413,15 & {$[\mathrm{M}+\mathrm{Na}]^{+}$} \\
\hline Acetylharpagide & 3,50 & 200 & 429,14 & {$[\mathrm{M}+\mathrm{Na}]^{+}$} \\
\hline Ajugoside & 3,67 & 200 & 413,14 & {$[\mathrm{M}+\mathrm{Na}]^{+}$} \\
\hline Oleuropein & 4,29 & 235 & 563,19 & {$[\mathrm{M}+\mathrm{Na}]^{+}$} \\
\hline Harpagoside & 5,17 & 278 & 517,16 & {$[\mathrm{M}+\mathrm{Na}]^{+}$} \\
\hline
\end{tabular}

by UV spectrophotometry and/or electrospray ionization time-of-flight mass spectrometery. Ionization was performed in positive ESI mode. Retention parameters (capacity coefficients K), UV absorbance maxima ( $\left.\lambda_{\max }\right)$, $\mathrm{m} / \mathrm{z}$ values in TOF-MS mode and $\mathrm{m} / \mathrm{z}$ identification are given in Table. The elaborated methodology is destined for the quality assessment of pharmaceutical raw materials and dietary supplements of herbal origin.

\section{ASSESSMENT OF CORRELATION BETWEEN THE CONTENT OF POLYPHENOLS, PROANTHOCYANIDINS AND ANTIOXIDANT ACTIVITY IN "IN VITRO" TESTS IN FOOD AND MEDICINAL RAW PLANT MATERIALS}

\section{(C) Perova I. B., Eller K. I.}

Institute of Nutrition RAMS, Moscow, Russia

Proanthocyanidins (OPC) or oligomers of catechins (flavan-3-ols) are among the most widespread forms of polyphenolic compounds of plant origin. According to the U.S. database (USDA Database for the Proanthocyanidin content of selected foods, 2004), proanthocyanidins provide more than $50 \%$ of the daily dietary intake of polyphenols. OPCs are widely used in food dietary supplements, medicinal and prophylactic nutrition and pharmaceuticals, enriched by antioxidants. The aim of this study was to investigate the correlation between the total content of polyphenolic compounds in $\mathrm{g}$ of gallic acid equivalent (GAE),

\begin{tabular}{|l|c|c|c|}
\hline Samples & Polyphenols, \% (g GAE/100g) & OPC, $\%$ & FRSA, trolox equivalent uM/g \\
\hline Cinnamon ground & $37,97 \pm 0,55$ & $5,13 \pm 0,09$ & $77750 \pm 380$ \\
\hline Lingonberry leaves & $13,48 \pm 0,04$ & $3,98 \pm 0,22$ & $2560 \pm 130$ \\
\hline Green tea powdered leaves & $6,65 \pm 0,26$ & $0,49 \pm 0,10$ & $2570 \pm 145$ \\
\hline Birch buds & $5,58 \pm 0,04$ & $0,21 \pm 0,02$ & $2555 \pm 125$ \\
\hline Origanum herb Herba Origani vulgaris & $3,66 \pm 0,04$ & $0,05 \pm 0,01$ & $2580 \pm 140$ \\
\hline Oak bark & $3,53 \pm 0,06$ & $1,05 \pm 0,14$ & $2632 \pm 130$ \\
\hline Green tea leaves & $3,44 \pm 0,06$ & $0,22 \pm 0,05$ & $2543 \pm 145$ \\
\hline Marsh cinquefoil stems Stipes Comari palustris & $2,97 \pm 0,06$ & $2,37 \pm 0,10$ & $2565 \pm 150$ \\
\hline Saint-John's wort herb & $2,58 \pm 0,09$ & $2,02 \pm 0,06$ & $2540 \pm 135$ \\
\hline Cocoa beans & $2,39 \pm 0,02$ & $1,54 \pm 0,09$ & $4375 \pm 170$ \\
\hline Rose hips & $2,21 \pm 0,04$ & $0,34 \pm 0,06$ & $2580 \pm 115$ \\
\hline Willow herb & $1,45 \pm 0,06$ & $0,13 \pm 0,03$ & $2400 \pm 140$ \\
\hline Herba Epilobii & & & $2590 \pm 120$ \\
\hline Walnuts & $1,44 \pm 0,06$ & $0,11 \pm 0,03$ & $2005 \pm 110$ \\
\hline Nutmeg & $1,13 \pm 0,04$ & $1,04 \pm 0,12$ & $3300 \pm 170$ \\
\hline Bilberry (wild) & $0,99 \pm 0,09$ & $0,24 \pm 0,05$ & $10600 \pm 240$ \\
\hline Red kidney beans & $0,95 \pm 0,14$ & $0,45 \pm 0,08$ & $1620 \pm 100$ \\
\hline Walnuts septum & $0,68 \pm 0,07$ & $0,42 \pm 0,06$ & $870 \pm 95$ \\
\hline Red grape peel & $0,47 \pm 0,07$ & $0,8 \pm 0,09$ & $980 \pm 90$ \\
\hline Sour cherry & $0,44 \pm 0,05$ & $0,36 \pm 0,06$ & $1150 \pm 90$ \\
\hline Viburnum opulus berries & $0,43 \pm 0,04$ & $0,19 \pm 0,03$ & $200 \pm 70$ \\
\hline Black currant & $0,16 \pm 0,03$ & $0,28 \pm 0,03$ & \\
\hline
\end{tabular}

